jURNAL Penelitian Hasil Hutan Vol. 38 No. 1, Maret 2020: 25-32

p-ISSN: 0216-4329

e-ISSN: 2442-8957

Terakreditasi Peringkat 2, No: 21/E/KPT/2018

\title{
PENGARUH EKSTRAK KAYU ULIN (Eusideroxylon zwageri) TERHADAP \\ SERANGAN RAYAP KAYU KERING (Cryptotermes cynocephalus Light): PENELITIAN PENDAHULUAN
}

\section{(The Effect of Ulin Wood Extracts (Eusideroxylon zwageri) Against Dry Wood Termite Attacks (Cryptotermes cynocephalus Light): A Preliminary Study)}

\author{
Mohammad Listianto Raharjo, Desi Mustika Amaliyah, Ratri Yuli Lestari, \\ \& Budi Tri Cahyana \\ Balai Riset dan Standardisasi Industri Banjarbaru \\ Jl. Panglima Batur Barat No. 2 Banjarbaru, Kalimantan Selatan 70711 \\ Telp. (0511) 4774861, 4772461, Faks. (0511) 4772115 \\ E-mail :m.listiantoraharjo@gmail.com
}

Diterima 15 Juli 2019, direvisi 6 Desember 2019, disetujui 3 Maret 2020

\begin{abstract}
Dry wood termites attack is one of the problems that cause huge losses in timber construction. One way to solve this problem is by preserving wood, with synthetic chemicals or natural ingredients. The purpose of this preliminary research was to determine the effect of ironwood powder extract as a natural wood preservative. Preservation methods conducted were cold immersion at normal temperature $\left( \pm 25^{\circ} \mathrm{C}\right)$ and hot immersion at $80^{\circ} \mathrm{C}$. Variations in the concentration are 5\%,10\%,15\%, and 20\%. Variation of immersion time are 1, 2, and 3 days for the cold immersion and 0.5; 1; 2; 3 hours for the hot immersion. Results show that mortality data and the degree of attack of dry wood termites. The results showed that the mortality of the dry wood termites increased 4-6\%. However, no difference was found on the degree of attacks between preserved and control wood.
\end{abstract}

Keywords: Dry wood termites, ironwood extract, rubberwood, preservation

\begin{abstract}
ABSTRAK
Serangan rayap kayu kering merupakan salah satu permasalahan yang menimbulkan kerugian besar. Salah satu cara mengatasinya adalah dengan pengawetan, baik dengan bahan kimia buatan ataupun bahan alami. Tujuan penelitian pendahuluan ini adalah untuk mengetahui pengaruh ekstrak kayu ulin sebagai bahan pengawet kayu alami. Metode pengawetan yang digunakan adalah untuk rendaman dingin pada suhu ruangan $\left( \pm 25^{\circ} \mathrm{C}\right)$ dan rendaman panas pada suhu $80^{\circ} \mathrm{C}$, dengan variasi konsentrasi bahan pengawet $5 \%, 10 \%, 15 \%$, dan $20 \%$. Variasi waktu rendaman yaitu 1, 2, dan 3 hari untuk rendaman dingin dan 0,$5 ; 1 ; 2$; dan 3 jam untuk rendaman panas. Hasil penelitian ini berupa data mortalitas dan derajat serangan rayap kayu kering. Dari data mortalitas, diperoleh kesimpulan bahwa terjadi peningkatan jumlah rayap yang mati sebesar 4-6\%, sedangkan dari data derajat serangan, tidak ditemukan perbedaan antara kayu yang telah diawetkan menggunakan ekstrak kayu ulin dan kayu tanpa pengawet.
\end{abstract}

Kata kunci: Rayap kayu kering, ekstrak kayu ulin, kayu karet, pengawetan 


\section{PENDAHULUAN}

Salah satu karakteristik kualitas kayu adalah keawetan atau ketahanan terhadap pengaruh faktor biologis dan non-biologis. Faktor biologis berupa serangan organisme perusak seperti bakteri, serangga, jamur, dan cacing laut (marine borer), sedangkan faktor non-biologis berupa gangguan secara fisika, kimia, dan mekanis Jasni, Pari, \& Satiti, 2016; Safitri, Hapid, \& Erniwati, 2014). Kayu sebagai bahan konstruksi atau furnitur memerlukan ketahanan yang baik terhadap organisme perusak terutama kumbang bubuk, rayap kayu kering, rayap tanah, jamur pelapuk, dan penggerek laut (SNI 7207, 2014). Kayu dengan ketahanan alami yang baik berasal dari kelompok yang tergolong kelas awet I (sangat awet) dan kelas awet II (awet) seperti ulin, merbau, jati, dan sonokeling. Kelemahan jenis pohon tersebut adalah tingkat pertumbuhannya relatif rendah (Dumanaw, 2007). Berbagai penelitian dilakukan dalam rangka pemenuhan kebutuhan kayu yang awet, antara lain dengan cara penambahan bahan pengawet ke bagian permukaan kayu (coating) atau bagian dalam kayu (impregnasi). Bahan pengawet ini berfungsi sebagai penolak (repellent), penarik (attractant), pemandul, atau pembunuh bagi serangga (Sholehah, 2011).

Rayap merupakan serangga perusak kayu yang telah banyak merugikan masyarakat. Jumlah anggota koloni rayap yang banyak dan wilayah jelajah yang luas menyebabkan tingkat kerusakan yang terjadi sangat tinggi (Subekti, 2010). Jenis rayap kayu kering (Cryptotermes cynocephalus Light.) umum ditemui di daerah tropis, termasuk Indonesia, dengan kerugian yang ditimbulkan mencapai 2,8 triliun rupiah tiap tahun (Pusat PenelitianBiomaterial,2018). Rayapinimenyerang kayu pada kondisi kering dan membentuk koloni di dalam kayu, serta meninggalkan butiran halus kotoran di sekitar kayu yang telah diserang (Suheryanto \& Haryanto, 2009).

Metode pengawetan yang digunakan pada penelitian ini adalah rendaman dingin dan panas. Keunggulan metode ini adalah jumlah kayu yang diawetkan banyak dalam sekali proses, larutan perendam dapat digunakan berulangulang, serta proses dan peralatan yang digunakan relatif sederhana (Suheryanto \& Haryanto, 2009). Bahan pengawet yang ditambahkan pada proses perendaman antara lain asam borat, formaldehida, dan Copper Chromium Boron (CCB). Penggunaan bahan kimia ini dapat meningkatkan keawetan kayu dengan sangat baik, namun memiliki dampak yang buruk terhadap lingkungan dan kesehatan manusia (Civardi, Schwarze, \& Wick, 2015). Pembatasan penggunaan bahan kimia yang berbahaya untuk bahan pengawet kayu terus dilaksanakan, seperti pelarangan penggunaan pengawet berbahan arsen pada tahun 2008 (Suhaendah \& Siarudin, 2015). Penelitian mengenai bahan pengawet kayu berbahan alami dilakukan guna memperoleh pengawet yang ramah lingkungan dan tidak mengganggu kesehatan manusia perlu dilakukan. Penelitian ini bertujuan memperoleh data penggunaan ekstrak kayu ulin (Eusideroxylon zwageri) sebagai bahan pengawet alami kayu terhadap serangan organisme perusak berupa rayap kayu kering (Cryptotermes cynocephalus Light.).

Penggunaan kayu ulin sebagai bahan konstruksi bangunan hingga perkapalan menghasilkan limbah pemotongan berupa serbuk gergajian (Martawijaya, Kartasujana, Mandang, Among Prawira, \& Kadir, 1989). Potensi pemanfaatan ekstrak kayu ulin sebagai bahan baku pengawet disebabkan kenyataan bahwa kayu ulin tergolong kelas awet I. Berdasarkan penelitian Bakri, Fahriza, dan Cahyana (2012), ekstrak kayu jati (kelas awet I) dapat digunakan sebagai bahan alami pengawet kayu dengan nilai mortalitas rayap mencapai 100\%. Ekstrak kayu jati juga dapat meningkatkan ketahanan kayu terhadap serangan jamur coklat dan jamur pembusuk (Brocco, Paes, Costa, Brazolin, \& Arantes, 2017). Penelitian ini juga diharapkan dapat meningkatkan nilai tambah limbah serbuk gergajian kayu ulin yang selama ini dimanfaatkan sebagai bahan bakar untuk memasak.

\section{BAHAN DAN METODE}

\section{A. Peralatan dan Bahan}

Peralatan yang digunakan adalah gergaji, kompor, panci maserasi, termometer, kain saring, jangka sorong, neraca analitik, gelas ukur, dan spektrofotometer. Bahan yang digunakan dalam penelitian berupa serbuk kayu ulin, air suling 


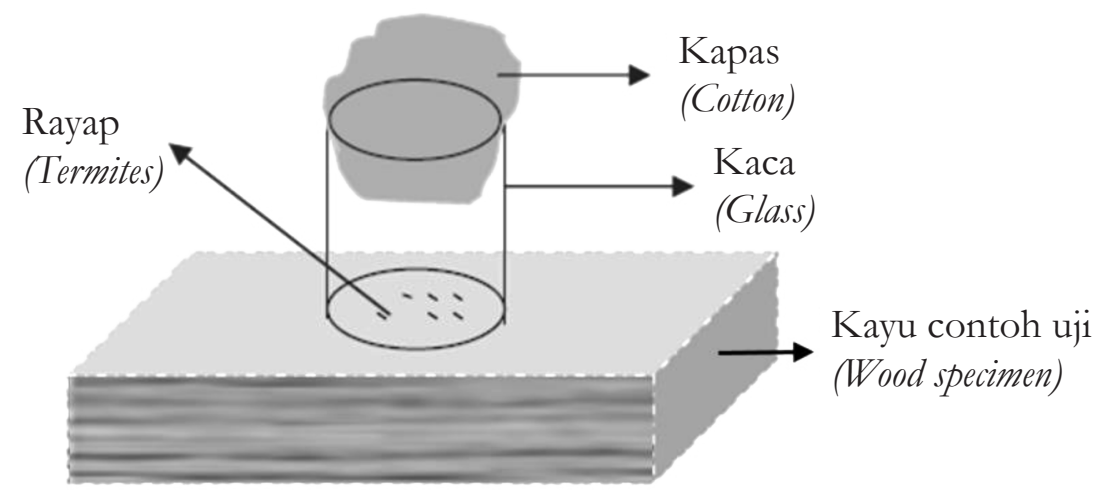

Gambar 1. Metode pengujian ketahanan terhadap rayap kayu kering Figure 1. Dry wood termite testing method

Sumber (Source): SNI 7207 (2014)

(aquadestilata), kayu karet sebagai sampel uji, cat kayu, dan bahan bakar gas. Serbuk kayu ulin merupakan limbah yang diperoleh dari tempat penggergajian kayu ulin sehingga bercampur antara bagian teras dan gubal, serta telah diayak dengan ayakan ukuran mesh 35. Kayu karet (Hevea brasilliensis Muell. Arg.) dipilih sebagai contoh uji dikarenakan memiliki tingkat keawetan terhadap rayap yang rendah hingga sedang (kelas awet IV-V). Kayu ini harus melalui pengawetan apabila hendak digunakan sebagai bahan bangunan dan furnitur (Sumaryanto, Hadikusumo, \& Lukmandaru, 2013).

\section{B. Metode Penelitian}

Pengujian kuantitatif kandungan bahan aktif dilakukan pada serbuk kayu ulin dengan menggunakan metode spektrofotometri (Adedeji, Ogunsanwo, \& Elufioye, 2017). Bahan aktif yang diuji yaitu saponin, tanin, total flavonoid, total fenolik, dan total alkaloid. Parameter ini dipilih karena merupakan pengawet alami pada kayu terhadap serangan rayap kayu kering (Azis, Prayitno, Lukmandaru, \& Listyanto, 2015; Jasni et al., 2016).

Bahan pengawet yang digunakan memiliki konsentrasi 5\% (b/v), 10\% (b/v), 15\% (b/v), dan $20 \%$ (b/v). Serbuk kayu ulin ditimbang dalam jumlah $1.750 \mathrm{~g}, 3.500 \mathrm{~g}, 5.250 \mathrm{~g}$, dan 7.000 g. Air suling sebanyak 35 liter ditambahkan pada masing-masing serbuk dan dipanaskan pada suhu $40^{\circ} \mathrm{C}$ selama satu jam. Hasil rebusan selanjutnya disaring untuk memisahkan endapan sehingga diperoleh ekstrak kayu ulin yang digunakan sebagai bahan pengawet pada penelitian ini.

Proses pengawetan dilakukan dengan dua metode yaitu perendaman panas (bot immersion) dan dingin (cold immersion). Metode perendaman panas yaitu contoh uji kayu direndam dalam bahan pengawet bersuhu $80^{\circ} \mathrm{C}$ selama 0,5 jam; 1 jam; 2 jam; dan 3 jam. Perendaman dingin dilakukan dengan bahan pengawet bersuhu ruang $\left( \pm 25^{\circ} \mathrm{C}\right)$ selama 1 hari, 2 hari, dan 3 hari. Skema pengujian dapat dilihat pada Gambar 1. Prinsip pengujian

Tabel 1. Klasifikasi ketahanan kayu terhadap rayap kayu kering Table 1. Classification of wood resistance to dry wood termites

\begin{tabular}{|c|c|c|}
\hline $\begin{array}{l}\text { Ketahanan } \\
\text { (Resistance) }\end{array}$ & $\begin{array}{l}\text { Derajat kerusakan kayu } \\
\text { (Wood damage degrees) }\end{array}$ & $\begin{array}{l}\text { Nilai } \\
\text { (Scores) }\end{array}$ \\
\hline Sangat tahan (Very resistant) & $\begin{array}{l}\text { Utuh, atau serangan sangat ringan } \leq 5 \% \\
\text { (Undamaged, or very slight attack } \leq 5 \%)\end{array}$ & 0 \\
\hline Tahan (Resistant) & Serangan ringan $6-15 \%$ (Slight attack $6-15 \%$ ) & 40 \\
\hline Sedang (Moderate) & $\begin{array}{l}\text { Serangan sedang, berupa saluran-saluran yang dangkal dan sempit } \\
16-30 \% \text { (Moderate attack, shallow and narrow canals 16-30\%) }\end{array}$ & 70 \\
\hline Tidak tahan (Irresistant) & $\begin{array}{l}\text { Serangan berat, berupa saluran yang dalam dan lebar 31-50\% (Heavy } \\
\text { attack, deep and wide channels } 31-50 \% \text { ) }\end{array}$ & 90 \\
\hline Sangat tidak tahan (Susceptible) & Serangan sangat berat $>50 \%$ (Very heavy attack $>50 \%)$ & 100 \\
\hline
\end{tabular}

Sumber (Source): SNI 7207 (2014) 


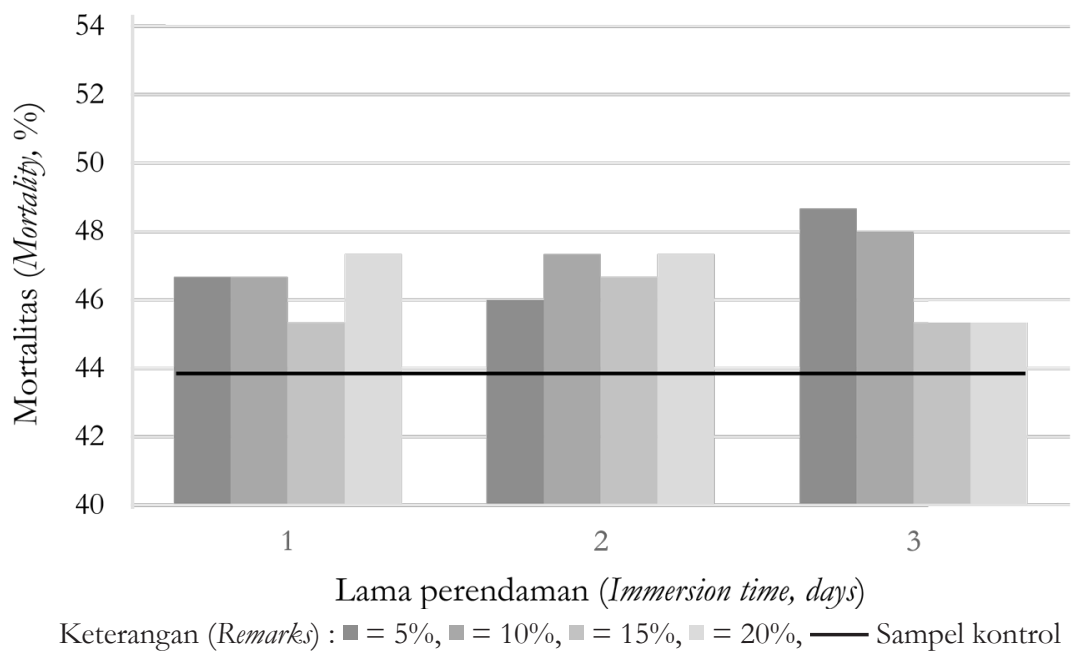

Gambar 2. Mortalitas rayap kayu kering pada kayu karet dengan pengawetan rendaman dingin

Figure 2. Mortality of dry wood termite on rubber wood with cold immersion preservation

ini adalah memaksa rayap kayu kering sejumlah 50 ekor pada tiap sampel untuk menyerang kayu dalam jangka waktu 12 minggu.

Derajat serangan adalah pembacaan secara visual seberapa besar kerusakan yang ditimbulkan oleh rayap kayu kering (SNI 7207, 2014). Hasil pengamatan visual kerusakan dikonversi menjadi nilai kuantitatif sesuai Tabel 2. Hasil penelitian ini terdiri dari dua hal yaitu mortalitas rayap kayu kering dan derajat serangan. Data mortalitas rayap kayu kering merupakan persentase perbandingan antara jumlah rayap yang mati dan jumlah rayap semula. Data ini memberikan gambaran efektivitas ekstrak kayu ulin sebagai zat anti rayap kayu kering. Semakin tinggi tingkat mortalitas, maka kayu aman terhadap serangan rayap kayu kering (Siswanto, Saputra, \& Amrulloh, 2011). Perhitungan nilai mortalitas dinyatakan dalam Persamaan (1).

Mortalitas $=\frac{\text { Jumlah Rayap Mati }}{\text { Jumlah Rayap Awal }} \times 100 \%$

\section{HASIL DAN PEMBAHASAN}

Analisis fitokimia dilakukan pada serbuk kayu ulin untuk mengetahui kandungan senyawa aktifnya. Kadar senyawa tertinggi berupa total flavonoid sebesar 12,28\% b/b serbuk kayu ulin, saponin 5,95\%; total fenolik 3,45\%; total alkaloid $1,54 \%$; dan $\operatorname{tanin} 0,78 \%$. Kandungan senyawa aktif tersebut merupakan bahan pengawet alami kayu terhadap serangan serangga, termasuk rayap kayu kering (Azis et al., 2015; Jasni et al., 2016).

Pengujian pengaruh ekstrak kayu ulin terhadap rayap kayu kering menghasilkan data mortalitas atau tingkat kematian rayap, seperti tercantum pada Gambar 2 untuk metode rendaman dingin dan Gambar 3 untuk metode rendaman panas. Sampel kontrol berupa kayu karet tanpa pengawetan menghasilkan nilai mortalitas $44,67 \%$, ditunjukkan dengan garis horizontal. Angka mortalitas ini setara dengan $22-23$ rayap mati selama masa pengujian.

Gambar 2 menunjukkan peningkatan persentase tingkat kematian rayap dibandingkan dengan kontrol. Rata-rata mortalitas rayap pada metode pengawetan rendaman dingin sebesar 46,72\%. Nilai tertinggi diperoleh pada perendaman ekstrak kayu ulin 5\% selama tiga hari, yaitu sebesar 48,67\%.

Nilai mortalitas tertinggi pada pengawetan rendaman panas sebesar $50,67 \%$, yaitu konsentrasi pengawet $15 \%$ dan lama perendaman 3 jam, dapat dilihat pada Gambar 3. Rata-rata mortalitas sebesar 47,54\% lebih tinggi dibandingkan dengan mortalitas pada pengawetan rendaman dingin. Priadi dan Pratiwi (2014) menyatakan bahwa rendaman panas dapat mengeluarkan udara dan uap air dalam pori-pori kayu sehingga penetrasi bahan pengawet dapat lebih optimal. Berdasarkan 


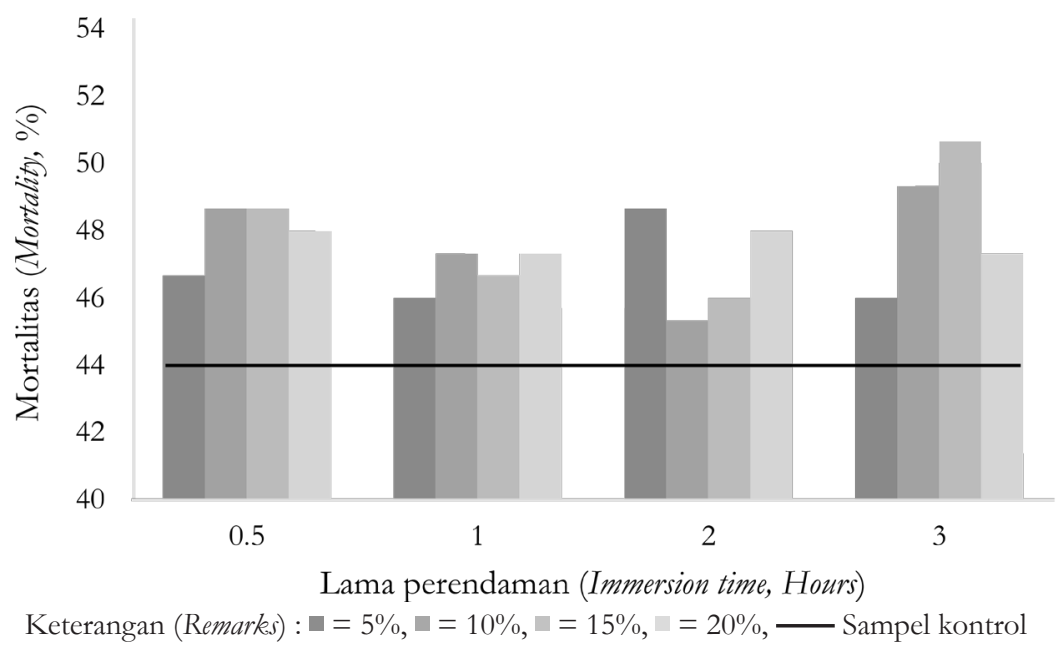

\section{Gambar 3. Mortalitas rayap kayu kering pada kayu karet dengan rendaman panas Figure 3. Mortality of dry wood termite on rubber wood with hot immersion}

Gambar 3, hubungan antara mortalitas dan lama perendaman memiliki tren grafik yang beragam. Pada konsentrasi pengawet 5\%, tren grafiknya menanjak hingga waktu perendaman 2 jam, namun mengalami penurunan pada waktu perendaman 3 jam. Pada bahan pengawet konsentrasi 10\% dan 15\% berbentuk tren batbtub curve dengan kenaikan tertinggi pada perendaman 3 jam. Konsentrasi 20\% memiliki tren grafik yang cenderung stabil. Dari Gambar 3 dapat diketahui bahwa lama perendaman memberikan dampak pada mortalitas rayap kayu kering. Waktu perendaman yang lebih lama menyebabkan tingkat kematian rayap.

Pengujian derajat serangan memberikan nilai yang sama pada tiap sampel uji yaitu 70 . Nilai ini diperoleh dari pengamatan secara visual dampak serangan berupa saluran-saluran yang dangkal dan sempit. Hal ini menunjukkan bahwa intensitas serangan rayap kayu kering terhadap kayu karet yang telah diawetkan berada dalam kategori sedang. Pada sampel kontrol, derajat serangan rayap kayu kering juga berada dalam level sedang, yaitu bernilai 70 . Hal ini menunjukkan bahwa tidak terdapat pengaruh nyata antara pengawetan dengan variabel yang telah dilakukan terhadap intensitas serangan rayap kayu kering.

Berdasarkan data mortalitas dan derajat serangan, dapat disimpulkan bahwa ekstrak kayu ulin konsentrasi 5\% hingga 20\% memiliki kadar toksisitas yang rendah sehingga belum optimal jika digunakan sebagai bahan anti rayap kayu kering. Menurut Barly, Abdurrahim, dan Permadi (1995) dalam Batubara, Rosamah, dan Budiarso (2008), terdapat empat hal yang dapat mempengaruhi hasil pengawetan kayu yaitu jenis kayu, keadaan kayu pada waktu diawetkan, metode pengawetan, dan sifat bahan pengawet yang digunakan.

Sampel uji merupakan kayu karet yang memiliki kerapatan cukup tinggi, yaitu $0,6-0,75$ $\mathrm{g} / \mathrm{cm}^{3}$. Anatomi dan kerapatan kayu berpengaruh terhadap tingkat retensi dan penetrasi bahan pengawet. Pada kayu karet, rata-rata nilainya sangat rendah yaitu kurang dari 10\% (Putri, Herawati, \& Batubara, 2013), namun keterbatasan pada penelitian ini adalah tidak dilakukannya pengujian retensi dan penetrasi bahan pengawet ekstrak kayu ulin terhadap sampel kayu karet. Kadar air kayu sebelum pengawetan juga memiliki dampak terhadap hasil penelitian. Semakin rendah kadar air di dalam kayu maka rongga sel dapat terisi bahan pengawet sehingga tingkat absorbsi retensi lebih tinggi (Putri et al., 2013). Kadar air kayu sampel sebelum diawetkan sebesar $\pm 20 \%$, yaitu sesuai dengan kondisi kayu di dalam ruangan tanpa perlakuan pengeringan. Hal lain yang mempengaruhi hasil pengawetan adalah metode yang digunakan. Pada penelitian ini digunakan variasi suhu dan waktu perendaman. Penelitian sebelumnya menyatakan kayu karet memiliki nilai keawetan yang tinggi setelah direndam dengan pengawet CCB selama tujuh hari pada suhu kamar (Arsad, 2009) atau pengawet asam borat pada suhu $100^{\circ} \mathrm{C}$ dan dibiarkan dingin selama dua hari (Putri et al., 2013). 
Jenis dan konsentrasi bahan pengawet berbahan alam memiliki pengaruh besar terhadap efektivitas pengawetan kayu. Hal ini bergantung pada senyawa aktif yang berfungsi sebagai anti rayap, yaitu semakin tinggi kandungan senyawa aktif maka semakin baik pula kemampuan pengawetkayu tersebut. Kandungan senyawaaktif pada serbuk kayu ulin sebagai bahan penelitian ini belum mampu mengawetkan kayu karet dari serangan rayap kayu kering. Hal ini diduga karena kondisi pohon ulin yang menghasilkan serbuk tersebut. Faktor yang mempengaruhi kadar senyawa aktif antara lain umur pohon, status nutrisi, tempat tumbuh, dan masa penyimpanan (Adedeji et al., 2017). Bahan baku yang digunakan pada penelitian ini yaitu serbuk limbah gergajian kayu ulin yang tidak dapat ditelusuri kondisi kandungan senyawanya. Beragam penelitian juga dilakukan untuk memperoleh data konsentrasi yang optimal untuk pengawet berbahan alam, misalnya daun pepaya pada konsentrasi 10\% pelarut etil asetat (Azis, Prayitno, Lukmandaru, \& Listyanto, 2018) dan daun tuba pada konsentrasi 6\% (Hidayatullah, Rizaldy, Gracia, \& Syahidah, 2017). Pada penelitian ini diperoleh data konsentrasi pengawet yang berbeda antara metode rendaman dingin dan panas. Konsentrasi $5 \%$ pada metode rendaman dingin menghasilkan data mortalitas tertinggi dengan tren meningkat seiring lama waktu perendaman. Pada metode rendaman panas, konsentrasi 15\% menghasilkan data mortalitas tertinggi dengan tren kenaikan mortalitas rayap kayu kering seiring lama waktu perendaman. Kedua hasil tersebut belum dapat dianggap sebagai konsentrasi optimal karena kenaikan mortalitas rayap kayu masih sangat rendah.

\section{KESIMPULAN}

Penelitian pendahuluan mengenai pengaruh ekstrak kayu ulin sebagai pengawet kayu terhadap serangan rayap kayu kering masih belum mendapatkan hasil yang diinginkan. Konsentrasi pengawet $(5 \%, 10 \%, 15 \%$, dan $20 \%)$ dan lama waktu perendaman meningkatkan nilai ratarata tingkat kematian rayap dari semula 44,67\% (sampel kontrol) menjadi $46,72 \%$ pada rendaman dingin dan 47,54\% pada rendaman panas.
Pada pengujian derajat serangan tidak terdapat perubahan antara sampel kontrol dan sampel uji yang telah diawetkan.

\section{UCAPAN TERIMA KASIH}

Penulis mengucapkan terima kasih kepada Badan Penelitian dan Pengembangan IndustriKementerian Perindustrian Republik Indonesia yang telah memberikan dana penelitian melalui Anggaran DIPA TA 2018.

\section{KONTRIBUSI PENULIS}

Ide, desain dan rancangan percobaan dilakukan oleh DMA, RYL, BTC. Pengambilan data dilakukan oleh MLR, DMA, RYL, BTC. Analisis data dilakukan oleh MLR, DMA dan penulisan manuskrip dilakukan oleh MLR, DMA. Perbaikan dan finalisasi manuskrip dilakukan oleh MLR, DMA.

\section{DAFTAR PUSTAKA}

Adedeji, G. A., Ogunsanwo, O. Y., \& Elufioye, T. O. (2017). Quantifications of phytochemicals and biocide actions of Lawsonia inermis Linn. extracts against wood termites and fungi. International Biodeterioration and Biodegradation, 116, 155-162. doi: 10.1016/j. ibiod.2016.10.026.

Arsad, E. (2009). Kayu karet sebagai substitusi kayu hutan alam untuk industri. Jurnal Riset Industri Hasil Hutan, 1(1), 31-37. doi: 10.24111/jrihh. v1i1.871.

Azis, A., Prayitno, T. A., Lukmandaru, G., \& Listyanto, T. (2015). Aktivitas antirayap ekstrak daun Orthosiphon sp., Morinda sp., dan Carica sp. Jurnal Ilmu Teknologi Kayu Tropis, 13(2), 161-175.

Azis, A., Prayitno, T. A., Lukmandaru, G., \& Listyanto, T. (2018). Aktivitas antirayap ekstrak daun pepaya dan kumis kucing. Jurnal Ilmu Teknologi Kayu Tropis, 16(1), 5267.

Bakri, S., Fahriza, A., \& Cahyana, B. T. (2012). Serbuk gergajian kayu jati (Tectona grandis) sebagai pengawet kayu durian (Durio zibethinus). Jurnal Riset Industri Hasil Hutan, 4(2), 1-5. 
Batubara, R., Rosamah, E., \& Budiarso, E. (2008). Identifikasi sifat ekstrak kulit kayu medang hitam (Cinnamomum prorrectum Roxb.) sebagai bahan pengawet kayu. Jurnal Kebutanan Tropika Humida, 1(1), 74-83.

Brocco, V. F., Paes, J. B., Costa, L. G. da, Brazolin, S., \& Arantes, M. D. C. (2017). Potential of teak heartwood extracts as a natural wood preservative. Journal of Cleaner Production, 142, 2093-2099. doi: 10.1016/j. jclepro.2016.11.074.

Civardi, C., Schwarze, F. W. M. R., \& Wick, P. (2015). Micronized copper wood preservatives: an efficiency and potential health risk assessment for copper-based nanoparticles. Environmental Pollution, 200(May), 126-132. doi: 10.1016/ j.envpol.2015.02.018.

Dumanaw, J. F. (2007). Mengenal kayu ( $7^{\text {th }}$ ed.). Yogyakarta: Kanisius.

Hidayatullah, S., Rizaldy, A. A., Gracia, H., \& Syahidah. (2017). Efikasi ekstrak daun tuba sebagai anti rayap alami. Jurnal Ilmu dan Teknologi Kayu Tropis, 15(2), 167-174.

Jasni, J., Pari, G., \& Satiti, E. R. (2016). Komposisi kimia dan keawetan alami 20 jenis kayu indonesia dengan pengujian di bawah naungan. Jurnal Penelitian Hasil Hutan, 34(4), 323-333. doi: 10.20886/ jphh.2016.34.4.323-333.

Martawijaya, A., Kartasujana, I., Mandang, Y. I., Among Prawira, S., \& Kadir, K. (1989). Atlas Kayu Indonesia Jilid II. Badan Penelitian dan Pengembangan Kehutanan, Jakarta.

Priadi, T., \& Pratiwi, G. A. (2014). Sifat keawetan alami dan pengawetan kayu mangium, manii dan sengon secara rendaman dingin dan rendaman panas dingin. Jurnal Ilmu Teknologi Kayu Tropis, 12(2), 118-126.

Pusat Penelitian Biomaterial. (2018). Asosiasi Perusahaan Pengendalian Hama Indonesia (ASPPHAMI): Kerugian akibat rayap di indonesia capai triliunan rupiah. Diakses dari http://www.biomaterial.lipi.go.id/asp phami-kerugian-akibat-rayap-di-indonesiacapai triliunan-rupiah/pada 1 Juli 2019.
Putri, N., Herawati, E., \& Batubara, R. (2013). Pengawetan kayu karet (Hevea braziliensis Muell Arg) menggunakan asam borat (H3BO3) dengan metode pengawetan rendaman panas dingin. Peronema Forestry Science Journal, 2(1), 1-8.

Safitri, R., Hapid, A., \& Erniwati, E. (2014). Efektivitas bahan pengawet alami dari tanaman tembelekan (Lantana camara L.) pada beberapa jenis kayu terhadap serangan rayap tanah (Coptotermes Sp.). Warta Rimba, 2(2), 141-148.

Sholehah, D. N. (2011). Uji aktivitas anti rayap tembakau dan salak madura. Jurnal Agrovigor, 4(1), 127-132. doi: 10.21107/ agrovigor.v4i1. 276.

Siswanto, M. F., Saputra, A., \& Amrulloh, H. (2011). Pengaruh pengawetan bambu wulung dengan asap cair tempurung kelapa terhadap mortalitas rayap kayu kering. Dinamika Teknik Sipil, 11(2), 151-154.

Standar Nasional Indonesia (SNI). (2014). Uji ketahanan kayu terbadap organisme perusak kayu (SNI 7207-2014). Badan Standardisasi Nasional, Jakarta.

Subekti, N. (2010). Karakteristik populasi rayap tanah Coptotermes spp. (Blattodea : Rhinotermitidae) dan dampak serangannya. Biosaintifika, 2(2), 110-114.

Suhaendah, E., \& Siarudin, M. (2015). Pengawetan kayu ganitri dan mahoni melalui rendaman dingin dengan bahan pengawet boric acid equivalent. Jurnal Ilmu Teknologi Kayu Tropis, 13(2), 185-192.

Suheryanto, D., \& Haryanto, T. (2009). Pemanfaatan kayu karet untuk furniture. Dalam Prosiding Seminar Nasional Penelitian, Pendidikan dan Penerapan MIPA (pp. 1-8).

Sumaryanto, A., Hadikusumo, S. A., \& Lukmandaru, G. (2013). Pengawetan kayu gubal jati secara rendaman dingin dengan pengawet boron untuk mencegah serangan rayap kayu kering (Cryptotermes cynocephalus Light.). Jurnal Ilmu Kehutanan, 7(2), 93-107. doi: 10.22146/jik.7516. 
